\title{
Mejoramiento de la competencia escritural en la educación básica primaria a través de la mediación instruccional y pedagógica del video
}

\author{
Solfadys Díaz-Padilla* \\ aMagister en Prácticas pedagógicas. Docente Ministerio de Educación Nacional, \\ Secretaría de Educación Municipal de Cúcuta. \\ Forma de citar: Díaz, S. (2017). Mejoramiento de la competencia escritural en la educación básica \\ primaria a través de la mediación instruccional y pedagógica del video. Perspectivas, 2(1). 84-96
}

Recibido: julio 14 de 2016

Aceptado: noviembre 06 de 2016

\section{Palabras clave \\ Competencia escritural, escritura, mediación pedagógica del video, diseño instruccional, educación primaria}

Resumen: Esta investigación tuvo como objetivo general aplicar el modelo instruccional de Dorrego (1999) fundamentado en el uso pedagógico del video para evaluar la consolidación de la competencia escritural en los estudiantes de grado quinto de Básica Primaria. La metodología empleada es de carácter cuantitativo, basada en el estudio cuasi experimental. Se seleccionaron dos grupos, uno de control, con el que se trabajó con el texto escrito, y uno experimental,en el que se probó la intervención del video. El proceso inició con la aplicación de un pretest, sometido a evaluación mediante la rúbrica de composición de Colón (2003), que contiene las características principales de la producción escrita. Posteriormente se llevó a cabo un tratamiento de intervención para el mejoramiento de la producción textual. Se finalizó el estudio con un post-test evaluado con la misma rúbrica. Los resultados obtenidos evidencian que el video puede ser utilizado para mejorar la producción escrita, siguiendo las pautas del diseño instruccional y potencializando su uso.

\footnotetext{
* Autor para correspondencia

solfadys@gmail.com
} 


\section{Keywords}

Writing abilities, writing, pedagogical video tool, instructional design, primary education

\section{Palavras chave \\ Competência bíblica, escrita, video mediação pedagógica, design instrucional, educação primária}

\section{Improvement of scriptural competence in primary basic education through the instructional and pedagogical mediation of video}

\begin{abstract}
The overall objective of this study was to apply the instructional model of Dorrego (1999), hinged on the pedagogical use of video to evaluate the consolidation of writing abilities in fifth-grade students of Basic Primary Education. The methodology used was of a quantitative nature, based on the semi-experimental study. Two groups were selected: one of control, which worked on the written text, and an experimental group, in which the intervention of the video was tested. The process began with the application of a pretest, subjected to evaluation through Colon's writing rubric, which contains the main characteristics of written production (2003). Subsequently, an intervention treatment was carried out to improve the textual production. The study was completed with a post-test, evaluated with the aforementioned rubric. The results obtained highlight that the video could be used to improve written production, following the guidelines of the instructional design and enhancing its use.
\end{abstract}

\section{Melhoria da competência bíblica no ensino básico primário através da mediação pedagógica e instrucional de vídeo}

Resumo: O objetivo principal desta pesquisa foi aplicar o modelo instrucional de Dorrego (1999) com base no uso pedagógico do vídeo para avaliar a consolidação da competência literária em alunos da quinta série da Primária Básica. A metodologia utilizada é quantitativa, com base no estudo quase-experimental. Foram selecionados dois grupos, um de controle, com o qual se trabalhou com o texto escrito, e um experimental, no qual a intervenção do vídeo foi comprovada. $\mathrm{O}$ processo começou com a aplicação de um pré-teste (assinado por Colon, 2003) que contém as principais características da produção escrita. Posteriormente, um tratamento de intervenção foi realizado para melhorar a produção textual. O estudo foi concluído com um pósteste avaliado com a mesma rubrica. Os resultados obtidos mostram que o vídeo pode ser usado para melhorar a produção escrita, seguindo as diretrizes de design instrucional e aprimorando seu uso. 


\section{Introducción}

En el campo pedagógico los profesores están llamados a crear pensamientos reflexivos y críticos frente a la realidad educativa del país, de manera que a partir de una nueva mirada del docente se encuentren soluciones a los problemas educativos y se actualice el que hacer pedagógico.

En este sentido, la investigación que se reporta se propone ofrecer un aporte concreto en un aspecto específico de la enseñanza, relacionado con la aplicación del modelo instruccional de Dorrego (1999), fundamentado en el uso pedagógico del video, para el mejoramiento de la competencia escritural entre los estudiantes del grado quinto de Básica Primaria en el Departamento de Córdoba, Colombia.

Esta investigación es parte de un proyecto mayor relacionado con el estudio de las dificultades de escritura que presentan los estudiantes en San Antero, Departamento de Córdoba. Su propósito general consiste en la redimensión de las prácticas pedagógicas de los docentes en función del uso de medios audiovisuales, y específicamente el video, como una herramienta pedagógica cargada de significados, adecuada al contexto escolar, que genera procesos de enseñanza aprendizaje constructivos, de fácil manejo, bajo costo y eficiente como instrumento de evaluación y propiciador de actitudes y valores adecuados desde los diferentes ambientes de aprendizaje.

Desde esta perspectiva, el video se presenta como una herramienta útil en el ámbito educativo, lo cual permite dinamizar el proceso de aprendizaje de los estudiantes, y proporciona estrategias de enseñanza claves en el aula, pues según Ferres (1994: 47):

La importancia de utilizar el video de manera organizada con un fin pedagógico concreto, las bondades que se obtienen son muy variadas, incluyendo no solo el aspecto motivacional, sino también la retroalimentación, que apunta a fomentar un aprendizaje significativo $y$ cualificado.
Esta experiencia revaloriza el video como medicación pedagógica, en la medida en que permite mejorar la competencia escritural, una habilidad que se fortalece intencionalmente a través de las prácticas pedagógicas desde las diferentes áreas Jaimes, L.(2017). En efecto, la escritura constituye una herramienta indispensable para desarrollar las habilidades comunicativas cuando los estudiantes deben argumentar, exponer ideas, discutir, describir y tomar apuntes. De acuerdo con Vásquez Rodríguez (2000) el proceso de escritura consiste en "poner afuera nuestro pensamiento, es poner nuestro yo", lo que significa que la escritura es el medio por el cual el pensamiento se da a conocer a los otros.

Con el fin de fortalecer el uso del video como una herramienta pedagógica se aplicó el diseño instruccional de Dorrego(1999),que permite abordar contenidos a través de unas especificaciones de secuenciación determinadas en un plan didáctico fundamentado en la teoría cognitiva de Gagné (1970), como una estrategia pedagógica para mejorar la competencia escritural. Los textos escritos fueron evaluados mediante un instrumento propuesto por Colón (2003) denominado rúbrica para evaluar las características principales de una composición.

De esta manera, la investigación trazó como ruta metodológica con un diseño cuasi experimental desde el paradigma cuantitativo. Como muestra fueron seleccionados aleatoriamente dos grupos, denominados grupo control, en el cual se utilizó el texto impreso, y grupo experimental, en el que se usó pedagógicamente el video. En los dos grupos se intervino el diseño instruccional para promover el mejoramiento en la competencia escritural. Ambos fueron evaluados al inicio (pre-test) y al final (post- test) del tratamiento mediante la rúbrica para evaluar las características principales de la composición (Colón, 2003).

El estudio se realizó a partir de la concepción de la práctica pedagógica como herramienta transformadora desde la realidad de los profesores colombianos. Se pensó concretamente que el diseño 
instruccional de Dorrego (1999) podría resultar útil para innovar en el aula de clases, en cuanto a competencias escriturales se refiere, haciendo uso del video como una instrumento que requiere de jóvenes autónomos, comunicativos, independientes y creativos, capaces de aprender a aprender. En consecuencia, en el presente estudio se planteó como propósito evaluar la efectividad del uso video como recurso de mediación instruccional y pedagógico para valorar la consolidación de la competencia instruccional en la educación primaria, a partir de un estudio cuasi experimental que permite evaluar la presencia de diferencias significativas asociadas a una intervención pedagógica del uso del video que narra una historia adaptada a la edad de los niños del estudio.

\section{Materiales y métodos}

El presente estudio se desarrolló bajo el enfoque cuantitativo, siguiendo una metodología con diseño cuasi experimental, con un conjunto de estudiantes de educación primaria. Se conformaron dos grupos de trabajo (experimental y de control). Con el fin de evaluar las diferencias significativas entre los dos grupos se intervinieron mediante un diseño instruccional para promover el mejoramiento en la competencia escritural. Cada grupo se evaluó al inicio a través de un pre-test y al final de la intervención con el post-test.

Utilizando el diseño de pre-test y post-test, y con los datos recabados al comienzo y final del periodo experimental con los dos grupos, se procedió a evaluar los resultados obtenidos con el propósito de inferir si existían o no diferencias significativas entre tratamientos (experimental y control), pues tal y como describen Hernández, et al. (2006: 136), se propone "administrar un estímulo o tratamiento experimental a uno de los dos grupos y finalmente se le aplicará una prueba posterior al estímulo".

El estímulo que se aplicó con miras a fortalecer la competencia escritural fue la implementación del uso pedagógico del video en el grupo experimental.
Se tomó como referencia el manejo de este medio audiovisual por parte de Ferrés (1994), uno de los pilares teóricos de esta experiencia, $\mathrm{y}$, quien a su vez define las modalidades del video y destaca algunas de sus funciones en la enseñanza. En el caso particular de esta investigación, se utilizó la modalidad programa motivador.

\subsection{Población y muestra}

Se consideró como población los estudiantes el grado quinto de básica primaria de la Institución Educativa Julio Miranda, sede Señora del Carmen, San Antero (Córdoba). La muestra fue seleccionada de manera aleatoria y consistió en dos grupos: grupo control (con los cuales se trabajó el texto impreso) y grupo experimental (en los que usó pedagógicamente el video).

\subsection{Instrumento}

Una vez planificada la experiencia se aplicó el pre- test a los dos grupos ya conformados. Los contenidos del test están relacionados con los elementos de la estructura narrativa. El ejercicio verbal se propone a partir de una imagen. En este caso, se organizó una historia que fue narrada mediante la participación de los estudiantes. Con posterioridad a la intervención se aplicó el posttest, en el cual se planteó una secuencia de imágenes como elemento base para desarrollar el proceso de escritura. Se ha tenido en cuenta en este proceso la experiencia de Schneider (1996), que analizó los textos narrativos orales producidos por niños de 5 a 9 años en tres condiciones diferentes, una de las cuales incluía la utilización de imágenes para la producción textual. Según sus resultados, esta fue la estrategia mediante la cual se alcanzaron desempeños muy superiores en las narraciones infantiles. 


\subsection{Procedimiento}

El planteamiento metodológico de esta investigación corresponde a un diseño cuasiexperimental que se desarrolló en cinco fases. Para el trabajo pedagógico con los grupos de control y experimental se seleccionó la historia titulada: "Marco, de los Apeninos a los Andes", significativa para los estudiantes de primaria. La historia narra la travesía vivida por un niño italiano de trece años en busca de su madre durante la cual tuvo que enfrentar una serie de aventuras y dificultades. Como analogía, el grupo de investigación planteó su metodología en términos de un viaje: 1. Preparación del equipaje (planificación); 2.Puerto inicial (pretest); 3 . Ruta de aventura (tratamiento en los grupos experimental y control); 4. Puerto final (post-test) y por último 5. Valoración de la experiencia.

En la fase de planeación llamada "preparación del equipaje" se diseñó una guía para cada uno de los capítulos teniendo en cuenta el contenido del texto y el video. Los aspectos evaluados en la rúbrica fueron contenido, organización, uso del lenguaje, vocabulario y gramática, ortografía, acentuación y puntuación, y los intereses de los estudiantes, por lo cual se plantearon actividades lúdicas, motivadoras que se relacionaran con las diferentes áreas del currículo. Dentro de cada uno de los capítulos se establecieron unos cortes planeados intencional y pedagógicamente que buscaban hacer coincidir lo planteado en los dos medios (impreso y audiovisual), desarrollar procesos de comprensión y predicción sobre lo visto o leído y facilitar la focalización de la atención y la verificación del procesamiento de la información.

Durante la fase de planeación también se organizaron los recursos y materiales a utilizar, tales como edición del video, acomodación e impresión del texto (uno por estudiante del grupo control), diseño e impresión de afiches motivacionales, preparación de material didáctico adicional como carteles, canción, sopas de letras y acertijos. Igualmente, en el caso del grupo experimental se tuvo en cuenta la logística del sitio de aplicación: consecución e instalación de recursos, sala de audiovisuales, video beam, computador portátil, parlantes, amplificadores, extensiones y demás accesorios requeridos.

Una vez el equipaje estuvo listo, en la segunda fase, llamada "puerto inicial" se aplicó el pretest. Cabe aclarar que antes de la aplicación del instrumento se ambientó a los estudiantes de los dos grupos frente a los elementos y estructura narrativa haciendo un ejercicio verbal a partir de una imagen. En este ejercicio se organizó una historia contando con la participación de los estudiantes. Para la aplicación del post- test se planteó una secuencia de imágenes como elemento base para desarrollar el proceso de escritura, teniendo como referencia a Schneider (1996), quien analizó los textos narrativos orales producidos por niños de 5 a 9 años.

Durante la intervención o fase denominada "ruta de aventura" se aplicó el tratamiento a los dos grupos de investigación fundamentados en el diseño instruccional de Dorrego (1997) de la manera que sigue:

Grupo control: proceso sin intervención del video: La información se presentó en forma de texto escrito, con ausencia total de imágenes y se desarrolló una guía de aprendizaje por cada uno de los cuatro capítulos del mismo, favoreciendo el desarrollo de los diferentes aspectos que se deben tener en cuenta al componer un texto narrativo.

Grupo experimental: proceso mediado con intervención del video. La preparación de las clases se realizó con base en las fases del modelo de diseño instruccional de Dorrego (1999). Para el caso de esta experiencia se llevaron a cabo los siguientes momentos: centrar la atención, informar los objetivos, estimular los recuerdos, presentar el material, guiar el proceso, ejecutar la redacción y evaluar el desempeño, promover los procesos de retención y transferencia. Se empleó una secuencia para garantizar el desarrollo del plan didáctico de Dorrego (1997) y evidenciar el desarrollo de las fases del proceso de aprendizaje según la teoría cognoscitiva de Gagné (1970). 


\section{Resultados y discusión}

Un primer aspecto que resaltar en los resultados es el hecho de que en el grupo control no hubo diferencias significativas entre el pre-test y el posttest (valor $p>0.05$ ). El intervalo de confianza del 95\% para la diferencia incluye el cero (0), lo que demuestra que la competencia escritural no varió de manera significativa por la intermediación del texto.

En el grupo experimental, sí hubo diferencias significativas entre el pre-test y el post-test (valor $\mathrm{p}<0.05$ ). Así mismo, el intervalo de confianza del 95\% para la diferencia no incluye el cero (0), lo que demuestra que la competencia escritural varió de manera significativa por la intermediación del video. En cuanto a la efectividad de la mediación pedagógica (video) para mejorar la competencia escritural en estudiantes de quinto $\left(5^{\circ}\right)$ primaria, entre las mediciones efectuadas antes de la intermediación (pre-test) y después de la intermediación (posttest) hubo un incremento de 7.8 en la valoración promedio.

La media en la medición de inicio (pre-test) en el grupo control, fue 30.73 y en el grupo experimental 29.70. Aunque es 1.03 menor en el grupo experimental, la prueba de la diferencia de medias para muestras independientes (grupo control; grupo experimental), demuestra que no existen diferencias significativas en cuanto a la competencia escritural. La anterior afirmación se demuestra en el intervalo de confianza del $95 \%$ en el cual se incluye el valor cero (0) para la diferencia. Por otra parte, la prueba de Levene para la homogenización de varianzas tiene valor $p>0.05$, lo que supone varianzas iguales, condición necesaria para dar validez a la prueba aplicada (prueba t). Además, reafirma que los estudiantes, tanto del grupo control como del grupo experimental, inicialmente tenían el mismo nivel de competencia escritural.

En relación con las diferencias de muestras pareadas para cada una de las características de la composición de la competencia escritural (contenido, organización, vocabulario gramática, uso del lenguaje y ortografía), se plantearon y probaron las siguientes hipótesis:

H0: No hay diferencias entre la medición de inicio (pre-test) y la medición final (post-test), en el mejoramiento de la competencia escritural de manera individual en cada una de las características de la composición (contenido, organización, vocabulario gramática, uso del lenguaje y ortografía); y Ha: Sí hay diferencias. La tabla 1 muestra el resultado de las pruebas ejecutadas.

Tabla 1

Evaluación de diferencias significativas en los resultados por características de la composición en el pre-test y post-test

\begin{tabular}{|c|c|c|c|c|c|c|c|c|}
\hline & \multicolumn{5}{|c|}{ Diferencias Relacionadas } & \multirow{3}{*}{ t } & \multirow{3}{*}{ gl } & \multirow{3}{*}{$\begin{array}{l}\text { Sig.(Bilater } \\
\text { al) }\end{array}$} \\
\hline & \multirow[t]{2}{*}{ Media } & \multirow[t]{2}{*}{ Desviación tip. } & \multirow{2}{*}{$\begin{array}{l}\text { Error tip. De la } \\
\text { media }\end{array}$} & \multicolumn{2}{|c|}{$\begin{array}{l}\text { 95\% Intervalo de confianza } \\
\text { para la diferencia }\end{array}$} & & & \\
\hline & & & & Inferior & Superior & & & \\
\hline $\begin{array}{l}\text { Par } 1 \text { pre-test } \\
\text { Contenido- } \\
\text { Post- test }\end{array}$ & & & & & & & & \\
\hline Contenido. & $-2,5500$ & 2,9646 & 0,6628 & $-3,9373$ & $-1,1627$ & $-3,847$ & 19 & 0,001 \\
\hline $\begin{array}{l}\text { Par } 2 \text { Pre-test } \\
\text { Organización- } \\
\text { Post-test }\end{array}$ & & & & & & & & \\
\hline Organización & $-1,6000$ & 2,1126 & 0,4724 & $-2,5887$ & $-0,6113$ & $-3,387$ & 19 & 0,003 \\
\hline $\begin{array}{l}\text { Par } 3 \text { Pre-test } \\
\text { Vocabulario } \\
\text { Gramática-Post- } \\
\text { test Vocabulario }\end{array}$ & & & & & & & & \\
\hline Gramática & $-1,8000$ & 1,7045 & 0,3811 & $-2,5977$ & $-1,0023$ & $-4,723$ & 19 & 0,000 \\
\hline $\begin{array}{l}\text { Par } 4 \text { Pre-test } \\
\text { Uso del } \\
\text { Lenguaje- Post- } \\
\text { test Uso del }\end{array}$ & & & & & & & & \\
\hline Lenguaje & $-1,7500$ & 2,1613 & 0,4833 & $-2,7615$ & $-0,7385$ & $-3,621$ & 19 & 0,002 \\
\hline $\begin{array}{l}\text { Par } 5 \text { Pre-test } \\
\text { Ortografía- } \\
\text { Post- testo } \\
\text { Ortografía }\end{array}$ & $-0,1000$ & 0,2052 & 0,0459 & $-0,196$ & $-0,004$ & $-2,179$ & 19 & 0,042 \\
\hline
\end{tabular}


Con base en los resultados presentados en la tabla 1 se puede concluir que existen diferencias significativas en todas las composiciones, es decir, existe suficiente evidencia estadística para rechazar la hipótesis nula (H0). En otras palabras, la competencia mejora con la intermediación pedagógica (video) y en orden de influencia se encuentra contenido, vocabulario, gramática, uso del lenguaje organización, y por último ortografía, de acuerdo con la magnitud en el cambio del promedio.

Los resultados de la prueba $t$, con muestras relacionadas para evaluar las diferencias entre grupos se muestran en la tabla 2. En el grupo control, hubo diferencias significativas entre el pretest y el post-test (valor $\mathrm{p}<0.05$ ). Así mismo, el intervalo de confianza del $95 \%$ para la diferencia de medias no incluye cero (0), lo que demuestra que la competencia escritural no varió de manera significativa por la intermediación del texto.

En cuanto a la efectividad de la mediación pedagógica (video) para mejorar la competencia escritural en estudiantes de quinto $\left(5^{\circ}\right)$ primaria, entre las mediciones efectuadas antes de la intermediación (pre-test) y después de la intermediación (posttest) hubo un incremento de 4.37 en la valoración promedio.

Tabla 2

Evaluación de diferencias significativas en los resultados por grupos en el pre-test y post-test

Paired Differences

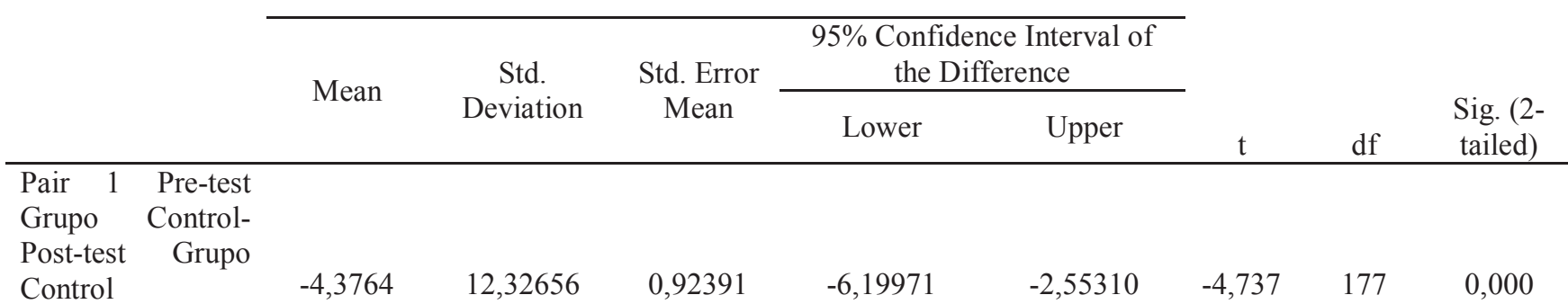

\begin{tabular}{lllllllll}
\hline Pair 2 Pre-test & & & & & & & \\
Grupo \\
Experimental- & $-8,03736$ & 10,94759 & 0,82993 & $-9,67546$ & $-6,39925$ & $-9,684$ & 173 & 0,000
\end{tabular}

Post-test Grupo

Experimental

Fuente: Autor, Proceso de investigación

En el grupo experimental, hubo diferencias significativas entre el pre-test y el post- test (valor $\mathrm{p}<0.05$ ). Así mismo, el intervalo de confianza del $95 \%$ para la diferencia no incluye a cero (0), lo que demuestra que la competencia escritural varió de manera significativa por la intermediación del video. En cuanto a la efectividad de la mediación pedagógica (video) para mejorar la competencia escritural en estudiantes de quinto primaria, entre las mediciones efectuadas antes de la intermediación (pre-test) y después de la intermediación (posttest) hubo un incremento de 8.03 en la valoración promedio.

Del análisis anterior se concluye que la mediación pedagógica utilizando el video para mejorar la competencia escritural da mejores resultados que utilizando el texto, dado que el promedio en la primera mejoró en 8.03 , y en la segunda mejoró en 4.37 . 
Tabla 3

Estadísticos descriptivos por grupos para muestras relacionadas pre-test y post-test

\begin{tabular}{clcccc} 
& Mean & N & Std.Deviation & Std. Error mean \\
\hline Pair 1 & Pre-test Grupo Control & 41,0899 & 178 & 18,98686 & 1,42313 \\
\cline { 2 - 5 } & $\begin{array}{l}\text { Post-test } \\
\text { Grupo } \\
\text { Control }\end{array}$ & 45,4663 & 178 & 18,9495 & 1,42033 \\
\hline Pair 2 & $\begin{array}{l}\text { Pre-test Grupo } \\
\text { Experimental }\end{array}$ & 42,0549 & 174 & 19,44233 & 1,47392 \\
\cline { 2 - 5 } & $\begin{array}{l}\text { Post-test Grupo } \\
\text { Experimental }\end{array}$ & 50,0920 & 174 & 19,61052 & 1,48667
\end{tabular}

Fuente: Autor, Proceso de investigación

La tabla 3 permite observar que en la medición de inicio (pre-test) en el grupo control es de41.09 y en el grupo experimental de 42.05. Aunque es 0.965 mayor en el grupo experimental, la prueba de la diferencia de medias para muestras independientes (grupo control; grupo experimental), demuestra que no existen diferencias significativas en cuanto a la competencia escritural. La anterior afirmación se demuestra en el intervalo de confianza del $95 \%$ en el cual incluye el valor cero (0) para la diferencia. Por otra parte, la prueba de Levene para la homogenización de varianzas tiene (valor $\mathrm{p}>0.05$ ), lo que supone varianzas iguales. Además, reafirma que los estudiantes tanto del grupo control como del grupo experimental, inicialmente tenían el mismo nivel de competencia escritural.
También se pudo notar la diferencia de muestras pareadas para cada una de las características de la composición de la competencia escritural (contenido, organización, vocabulario, gramática, uso del lenguaje y ortografía) en el momento posterior a la intervención. Para evaluar esta situación se plantearon las siguientes hipótesis, H0: No hay diferencias entre la medición de inicio (pre-test) y la medición final (post-test), en el mejoramiento de la competencia escritural de manera individual en cada una de las características de la composición (contenido, organización, vocabulario, gramática, uso del lenguaje y ortografía) y Ha: Sí hay diferencias. Los resultados de las pruebas se muestran en la tabla 4.

Tabla 4

Evaluación de diferencias significativas con posterioridad a la intervención en los resultados por características de la composición en el pre-test y post-test

Diferencias Relacionadas

\begin{tabular}{|c|c|c|c|c|c|c|c|c|}
\hline & \multicolumn{5}{|c|}{ Diferencias Relacionadas } & \multirow{3}{*}{$\mathrm{t}$} & \multirow{3}{*}{ gl } & \multirow{3}{*}{$\begin{array}{c}\text { Sig. } \\
\text { (Bilateral) }\end{array}$} \\
\hline & \multirow{2}{*}{ Media } & \multirow{2}{*}{$\begin{array}{l}\text { Desviación } \\
\text { tip. }\end{array}$} & \multirow{2}{*}{$\begin{array}{l}\text { Error tip. De } \\
\text { la Media }\end{array}$} & \multicolumn{2}{|c|}{$\begin{array}{l}95 \% \text { Intervalo de confianza } \\
\text { para la diferencia }\end{array}$} & & & \\
\hline & & & & Inferior & Superior & & & \\
\hline Par 1 Pre-test & & & & & & & & \\
\hline $\begin{array}{l}\text { Contenido-Post- } \\
\text { test Contenido }\end{array}$ & $-3,0172$ & 4,5101 & 0,3419 & $-3,6921$ & $-2,3424$ & $-8,825$ & 173 & 0,000 \\
\hline
\end{tabular}




\begin{tabular}{|c|c|c|c|c|c|c|c|c|}
\hline $\begin{array}{l}\text { Par } 2 \text { Pre-test } \\
\text { Organización- } \\
\text { Post-test } \\
\text { Organización }\end{array}$ & $-1,8736$ & 2,4438 & 0,1853 & $-2,2392$ & $-1,5079$ & $-10,113$ & 173 & 0,000 \\
\hline $\begin{array}{l}\text { Par3 Pre-test- } \\
\text { Vocabulario } \\
\text { Gramática-Post- } \\
\text { test Vocabulario } \\
\text { Grámatica }\end{array}$ & $-1,5172$ & 2,2953 & 0,174 & $-1,8607$ & $-1,1738$ & $-8,719$ & 173 & 0,000 \\
\hline $\begin{array}{l}\text { Par } 4 \text { Pre-test Uso } \\
\text { del Lenguaje-Post- } \\
\text { test- Uso del } \\
\text { Lenguaje }\end{array}$ & $-2,0546$ & 3,5937 & 0,2724 & $-2,5923$ & $-1,5169$ & $-7,542$ & 173 & 0,000 \\
\hline $\begin{array}{l}\text { Par } 5 \text { Pre-test } \\
\text { Ortografía-Post- } \\
\text { test Ortografía }\end{array}$ & $-0,5086$ & 0,9051 & 0,0686 & $-0,6441$ & $-0,3732$ & $-7,412$ & 173 & 0,000 \\
\hline
\end{tabular}

Fuente: Autor, Proceso de investigación

Con base en los resultados encontrados en la intermediación pedagógica (video) y en orden de tabla 4 se puede concluir que existen diferencias influencia se encuentra contenido, uso del lenguaje, significativas en todas las composiciones, es organización, vocabulario gramática, y por último decir, existe suficiente evidencia estadística para ortografía, de acuerdo a la magnitud en el cambio rechazar la hipótesis nula (H0). En otras palabras, del promedio (ver tabla 5). todas causan la mejora en la competencia con la

Tabla 5

Estadísticos descriptivos por grupos para muestras relacionadas con posterioridad a la intervención en el pre-test y post-test

\begin{tabular}{|c|c|c|c|c|c|}
\hline & & Media & $\mathrm{N}$ & Desviación tip. & $\begin{array}{l}\text { Error tip. De } \\
\text { la media. }\end{array}$ \\
\hline & Pre-test Contenido & 13,345 & 174 & 5,8908 & 0,4466 \\
\hline \multirow[t]{2}{*}{ Par 1} & Post- test Contenido & 16,362 & 174 & 5,9614 & 0,4519 \\
\hline & Pre-test Organización & 8,092 & 174 & 3,7421 & 0,2837 \\
\hline \multirow[t]{2}{*}{ Par 2} & Post- test Organización & 9,966 & 174 & 3,7421 & 0,2849 \\
\hline & Pre-test Vocabulario Gramática & 7,276 & 174 & 3,4614 & 0,2624 \\
\hline \multirow[t]{2}{*}{ Par 3} & Pos-test Vocabulario Gramática & 8,793 & 174 & 3,6355 & 0,2756 \\
\hline & Pre-test- Uso del lenguaje & 10,761 & 174 & 5,0031 & 0,3793 \\
\hline \multirow[t]{2}{*}{ Par 4} & Post- test Uso del lenguaje & 12,816 & 174 & 5,5973 & 0,4243 \\
\hline & Pre-test Ortografia & 1,914 & 174 & 1,4648 & 0,111 \\
\hline Par 5 & Post-test Ortografía & 2,422 & 174 & 1,8242 & 0,1383 \\
\hline
\end{tabular}

Fuente: Autor, Proceso de investigación 


\section{Discusión}

La investigación estuvo encaminada principalmente a mostrar los efectos que genera la mediación pedagógica del video en el desarrollo de la competencia escritural, a través de una serie de estrategias pedagógicas soportadas en el diseño instruccional de Dorrego (1999). La población objeto de estudio fueron dos grupos del grado quinto de una institución educativa colombiana escogidos aleatoriamente. En uno de ellos se implementó la estrategia del video y se llamó grupo experimental; en el otro, se utilizó la mediación del texto escrito y fue identificado como grupo control. Los sujetos que conformaron la muestra se destacaron por poseer características comunes en cuanto a edad, estrato, contexto social y cultural, lo que permitió aplicar los instrumentos bajo las mismas condiciones.

El primer paso realizado en el campo de investigación fue la ejecución de un pre-test que diera muestra de los verdaderos niveles de escritura en el que se encontraban los estudiantes de ambos grupos antes de implementarse el tratamiento pedagógico con el texto o con el video. Los resultados de este ejercicio fueron analizados a través de la prueba de diferencia de medias para muestras independientes, el cual demostró que aunque en el grupo control la media fuede30.7yenelgrupoexperimentalde29.7, la diferencia es mínima, de tan solo 1.0 , y por tanto se pueden considerar que los dos grupos que participaron en el experimento eran homogéneos inicialmente por cuanto poseían habilidades semejantes en relación con la competencia escritora.

La etapa siguiente consistió en la aplicación del tratamiento pedagógico con el desarrollo del diseño instruccional de Dorrego (1997), quien determina un plan didáctico fundamentado en la teoría cognitiva de Gagné (1970). Esta estrategia pedagógica tuvo como propósito mejorar la competencia escritural. Bajo estas directrices se organizaron los planes didácticos y las guías de aprendizaje, que contemplaron estrategias instruccionales tales como centrar la atención, informar los objetivos, estimular los recuerdos, presentación del material y producir la ejecución.
Terminada la fase anterior, se realizó un postest, que al igual que el pre-test, dio como producto unas composiciones escritas realizadas por los estudiantes y evaluadas con la rúbrica propuesta por Colón(2003), la cual permitió cuantificar el desempeño obtenido en aspectos como contenido, organización, vocabulario, gramática, uso del lenguaje, ortografía, acentuación y puntuación del texto escrito. Las calificaciones señaladas en la rúbrica permitieron analizar el desempeño del grupo control mediante la prueba $\mathrm{T}$ de muestras apareadas, comparando simultáneamente pre-test y pos-test, dejando ver una diferencia en la media de 3,2, lo cual no fue muy significativo entre el resultado inicial (pre-test) y la mediación final (post-test), en cuanto al mejoramiento de la competencia escritural cuando se utiliza el texto escrito.

Por otro lado, los resultados estadísticos obtenidos en el grupo experimental muestran que en el pos-test hubo un mayor incremento de esta competencia, con un avance en el promedio de 7.8, luego de la intervención pedagógica del video. Lo anterior permite aceptar la hipótesis alternativa y destacar diferencias entre los dos grupos, cuyos miembros mostraron habilidades escriturales semejantes en el pre-test, pero al llegar a la aplicación del post-test el que demostró mayores avances fue el grupo experimental.

Del anterior análisis se pueden destacar los beneficios del video, que ha demostrado ser una herramienta utilizable en el contexto escolar para generar procesos de enseñanza aprendizajes constructivos, llenos de conocimientos. Esta afirmación se apoya en Ferrés (2008: 174), quien señala que "la imagen del video 'garantiza el aprendizaje' si se muestra más interesante para los estudiantes, ya que este es un medio que modifica los procesos profundamente". De este modo, el video de Marco "De los Apeninos a los Andes" que se utilizó como herramienta pedagógica en el grupo experimental reflejó en los textos escritos por los estudiantes actitudes y valores propios del individuo, importantes en la formación integral y adecuada para diferentes ambientes de aprendizajes. 
Otro aspecto que permite destacar las ventajas del video frente a la utilización del texto escrito es sin duda alguna la motivación que este genera en los procesos de enseñanza- aprendizaje. En efecto, fue notorio que los estudiantes pertenecientes al grupo experimental al enfrentarse al video lo hacían con mayor disposición y entusiasmo. Este hecho se vio reflejado positivamente en los resultados de la variación del grupo, el cual inicio en el pre- test, con un puntaje en la media de 29,7 y finalizó con una media en una escala superior de 37,5.

Sobre este particular, Cabero (1989: 114) señala que "los medios audiovisuales tienen poder motivador para captar y mantener la atención de los receptores, 'poder' que les es concedido a partir de las cargas emotivas y afectivas que se le suponen a la imagen en particular y a los medios audiovisuales en general, y el grado de semejanza con la realidad que suelen poseer".

Si bien es cierto que aquí se han destacados las bondades del video, existen muchos teóricos y pedagogos que refutan su funcionalidad en el aula, argumentando que es un instrumento distractor, que no conduce a conocimiento alguno. Este postulado queda sin soporte en esta investigación, que por otra parte demuestra que ninguna tecnología (incluyendo el video) resulta efectiva en el campo educativo si no va acompañada de una planeación pedagógica guiada por el docente, que requiere analizar estructuras y tener en cuenta procesos cognoscitivos dados en el proceso de enseñanzaaprendizaje. Queda claro, de este modo, que los medios no reemplazan al docente, sino que permiten potenciar buenas prácticas educativas, por antiguas que sean. Además, analizando los resultados nos damos cuenta de que aunque el diseño pedagógico de las actividades fue iguales para los dos grupos, al variar la estrategia del video y el texto quien mostró resultados más significativos fue el grupo experimental, intervenido con el video, y no el grupo control, mediado por el texto escrito.

Los estudiantes del grupo experimental produjeron textos que reflejan procesos cognitivos coherentes, acordes con la temática propuesta a través del video como herramienta pedagógica. En este sentido viene a colación la opinión de Morales (2002: 42), quien señala que "al escribir, se desarrolla el pensamiento, se aprende sobre la lengua, se aprenden contenidos y se aprende sobre la escritura misma" (p.42).

Así las cosas, la escritura favorece el aprendizaje de habilidades, más que la adquisición de conocimientos en el área del lenguaje; esto exige asumir la escritura como un proceso lleno de saberes, reflejado en la estructura del texto, del qué y cómo escriben los estudiantes. En este sentido se puede afirmar que la presente esta investigación ha permitido una evaluación confiable de los textos construidos por los estudiantes, evaluación efectuada mediante la rúbrica propuesta por Colón (2003), que facilitó la comparación, validación y confiabilidad de los resultados.

Esta valoración resultó muy importante en la investigación, pues permitió focalizar las debilidades y fortalezas en la estructura de los textos escritos realizados por los estudiantes. Por otra parte, desde esta práctica pedagógica se consideró necesario evaluar la composición escrita como una articulación de significados e ideas claras y coherentes, tal y como lo señala Díaz (1999).

A partir de los planteamientos anteriores se puede afirmar que el uso pedagógico del video es una estrategia que se puede utilizar para el desarrollo de habilidades cognitivas, en este caso específico, encaminadas a mejorar el proceso escritural.

\section{Conclusiones}

Durante estapesquisainvestigativasellevóacabo la aplicación de un tratamiento pedagógico siguiendo el diseño instruccional de Dorrego (1997), lo cual permitió que los estudiantes emplearan estrategias cognoscitivas de codificación y elaboración de la información a partir de la mediación pedagógica del video, y así crearan composiciones escritas lógicas y coherentes, producto de un proceso organizado en el cual se llevaron a cabo guías de aprendizaje que permitieron la selección, percepción, procesamiento y recuperación de la información. 
Del mismo modo, se evidenció que usando del video como herramienta pedagógica altamente motivadora y siguiendo las estrategias instruccionales según las fases de aprendizaje de Gagné (1970), se logra crear paso a paso procesos mentales más organizados, pues cada una de las estrategias previamente planificadas en el plan didáctico (centrar la atención, informar los objetivos, estimular los recuerdos, presentar el material, guiar el proceso, producir la ejecución, dar feedback, evaluar el desempeño y promover la retención y transferencia), condujeron al finalizar el tratamiento a la adquisición de un aprendizaje más coherente, que se vio reflejado en los resultados de las composiciones escritas hechas por los estudiantes en el pos-test.

El video en esta investigación no solo se presentó como una herramienta motivadora en el ámbito educativo, si no que logró posicionarse como una estrategia pedagógica cargada de significados y saberes que ofreció a los estudiantes oportunidades para desarrollar sus capacidades de aprendizajes, haciendo planteamientos críticos, al momento de articular y expresar sus ideas por escrito.

Este medio audiovisual, en tanto que forma parte de la cotidianidad de los niños, generó además un espacio de absoluta confianza y familiaridad en el que cada uno se desenvolvió cómodamente en su rol. En efecto, las imágenes acompañadas de contenidos y artificios sonoros produjeron en los estudiantes sentidos que no solo ejercitaron la memoria y el recuerdo, sino que también les abrió un sinnúmero de posibilidades para trascribir su mundo y su realidad a través de propuestas escriturales cargadas de alto contenido humano.

Ante panoramas de este tipo, Martín Barbero (1998) afirma que "el video se muestra como un instrumento que abre un mundo de posibilidades educativas, que está dispuesto para que el estudiante explore o pueda identificarse, el cual debe estudiarse y evaluarse desde la misma esencia de la técnica como son la imagen, el color y el sonido, pues con estos principios claros se puede llegar a influir en las competencias del estudiante de la manera que se desee".

El instrumento utilizado para valorar los productos textuales de los estudiantes, tanto en la pre-prueba como en la post-prueba, fue la Rúbrica para Evaluar las Características Principales de una Composición Escrita propuesta por Colón (2003). Con esta se hizo un estudio estadístico que permitió analizar que los criterios y niveles de dominio de las composiciones escritas en el post-test fueron más significativas que los promedios iníciales del pre-test, tanto en el grupo control como en el experimental. Sin embargo, los resultados fueron mucho más significativo y alentadores en el grupo experimental que en el grupo control.

Todo lo dicho confirma que la mediación pedagógica del video a través de la aplicación del modelo instruccional contribuyó a mejorar la producción escrita de los estudiantes de quinto grado. Esta afirmación está suficientemente soportada mediante resultados estadísticos confiables, con lo cual queda satisfecho el propósito inicial del trabajo.

\section{Referencias}

Cabero, J. (1991). Propuestas para la utilización del video en los centros. Sevilla: Universidad de Sevilla. Disponible en http://tecnologiaedu. us.es/cuestionario/bibliovir/119.pdf

Colón, H. (2003). Análisis comparativo de las puntuaciones en documentos escritos por estudiantes del Recinto de Ponce, los cuales fueron evaluados a través de rúbricas por la Facultad de Español e Inglés al inicio y al final del término académico 2003. San Juan de Puerto Rico: Universidad Interamericana.

Díaz, Á. (1999). Aproximación al texto escrito. Medellín: Universidad de Antioquia.

Dorrego, E. (1997). Diseño instruccional de los medios y estrategias cognitivas. Revista de medios de comunicación y educación, 8: 149155. Disponible en http://rabida.uhu.es/dspace/ bitstream/handle/10272/619/b1514804x. pdf? sequence $=1$ 
Dorrego, E. (1999). Flexibilidad en el diseño instruccional y nuevas tecnologías de la información y la comunicación. Disponible en http://cursoampliacion.una.edu.ve/disenho/ paginas/dorregoflexi.pdf

Fernández, C., Baptista, P., \& Baptista, M. (2010). Metodología de la Investigación (5a Ed). México: McGraw-Hill / Interamericana Editores, S.A. DE C.V

Ferrés J. (1994). Video y educación. Barcelona: Paidós.

Ferrés J. (2008). La educación como industria del deseo. Un nuevo estilo comunicativo. Barcelona: Paidós.

Gagné, R. (1970). Las condiciones del aprendizaje. Aguilar. Madrid.

Jaimes, L.(2017). Propuesta metodológica para la enseñanza de la química en la Educación Media apoyada en el aprendizaje basado en problemas (APB). Perspectivas. 2(2). 38-48

Martín Barbero, J. (1998). Heredando el futuro. Pensar la educación desde la comunicación. Cultura y Educación, 10: 17-34.

Morales, O. (2002). ¿Cómo contribuir con el desarrollo de las competencias de los estudiantes universitarios como productores de textos? Educere, 5(16): 385-389.

Schneider, P. (1996). Effects of pictures versus orally presented stories on story retellings by children with language impairment. American Journal of Speech-Language Pathology, 5: 86-96.

Vásquez Rodríguez, F. (2000). Oficio de maestro. Bogotá: Pontificia Universidad Javeriana. 